\title{
DETERMINATION OF OPTIMAL GEOMETRIC PARAMETERS OF THE WINDSHIELD DEVICE LIMITING THE SPRAY DRIFT BY WIND IN HERBICIDES SPRAYING
}

\author{
I.S. Kruk ${ }^{\mathrm{a}}$, O.V. Gordeenko ${ }^{\mathrm{b}}$, T.P Kot ${ }^{\mathrm{a}}$, Andrzej Marczuk ${ }^{\mathrm{c}^{*}}$, Jan Kamiński ${ }^{\mathrm{d}}$, Maciej Kubońe \\ ${ }^{a}$ Belorussian State University of Agrotechnology; Belarus \\ ${ }^{\mathrm{b}}$ Belorussian State Agricultural Academy, Belarus \\ ${ }^{c}$ Department of Agricultural and Transport Machines, University of Life Sciences in Lublin, Poland \\ ${ }^{\mathrm{d}}$ Department of Agricultural and Forestry Machines, Warsaw University of Life Sciences; Poland \\ ${ }^{\mathrm{e}}$ Institute of Agricultural Engineering and Informatics, University of Agriculture in Krakow, Poland \\ "Corresponding author: e-mail: andrzej.marczuk@up.lublin.pl
}

\begin{tabular}{|c|c|}
\hline ARTICLE INFO & ABSTRACT \\
\hline $\begin{array}{l}\text { Article history: } \\
\text { Received: July } 2015 \\
\text { Received in the revised form: } \\
\text { September } 2015 \\
\text { Accepted: October } 2015\end{array}$ & $\begin{array}{l}\text { The objective of the paper is to determine the optimal geometric } \\
\text { parameters of the windshield device limiting the spray drift by wind in } \\
\text { herbicides spraying. Tests were carried out with the use of the plan- } \\
\text { ning methods of experiments and statistical methods of processing of } \\
\text { the obtained results. The result of the research consisted in obtaining }\end{array}$ \\
\hline $\begin{array}{l}\text { Key words: } \\
\text { drop, } \\
\text { flow, speed, } \\
\text { movement, } \\
\text { trajectory, } \\
\text { drift, } \\
\text { windshield device }\end{array}$ & $\begin{array}{l}\text { with rectangular boards. It was found out that this device may be used } \\
\text { at the wind speed exceeding agrotechnological sizes. The research } \\
\text { results will be used in the work on devices protecting against wind at } \\
\text { a precise herbicides spraying. }\end{array}$ \\
\hline
\end{tabular}

\section{Введение}

Основной задачей химической защиты растений является снижение доз пестицидов при одновременном сохранении эффективности их действия. Частично данную задачу можно реализовать путем совершенствования методов доставки пестицидов к объекту обработки, в том числе с использованием оборудования для локального внесения. Основными методами использования средств защиты растений (СЗР) является наземное опрыскивание, которое по прогнозам будет использоваться в ближайшем будущем, при всей его кажущейся простоте, является сложнейшим технологическим процессом. Развитие данного метода основано на механике и физике образования и осаждения жидкостных капель различной степени дисперсности.

Механизм осаждения капель рабочего раствора пестицидов на обрабатываемую поверхность сложен и многообразен. Капля, оторвавшись от выброшенной из сопла распылителя струи жидкости, обладая запасом кинетической энергии, замедленно движется под действием силы тяжести и силы сопротивления среды. Спустя 
некоторое время, когда эти силы взаимно уравняются, капля достигает конечной скорости и движется по определенной траектории, параметры которой определяются начальными условиями истечения и состоянием окружающей среды (Гордеенко и др., 2011). При обработках в ветреную погоду на протяжении всего процесса падения, капля подвержена воздействию направленного воздушного потока (ветра). Он изменяет закономерности движения капли, но и оказывает значительное влияние на качество выполнения технологического процесса. Поэтому исследование закономерностей движения капель в различных климатических условиях является важной задачей при исследовании процесса сноса препарата ветром из зоны обработки и проектировании ветрозащитных устройств (Гордеенко и др., 2014).

\section{Цель и область работы}

Целью исследований являлется обоснование рациональных геометрических параметров пространственной ориентации механического ветрозащитного устройства снижающего снос препарата ветром при локальном внесении гербицидов.

Реализация поставленной цели предусматривала проведение экспериментальных исследований по обоснованию конструктивных параметров ветрозащитного устройства и особенностей выполнения технологического процесса при его использовании.

\section{Основная часть}

Защита факела распыленной жидкости от воздействия ветра - одно из условий проведения качественной химической обработки растений в оптимальные сроки. Наиболее эффективным способом защиты факела распыла и снижения величины или исключения сноса рабочего раствора пестицидов является использование ветрозащитных устройств. В результате анализа способов снижения потерь пестицидов из-за сноса и устройств защиты факела распыла от прямого воздействия ветра (Гордеенко и др., 2007, Крук и др. 2009, Крук и др. 2010, Каминьски и Крук, 2011) были предложены конструкции ветрозащитных устройств, рабочие поверхности которых выполнены в форме прямоугольных (рисунок 1а) (Крук и др., 2010) и изогнутых пластин (рисунок 1,б) (Крук и др., 2013).

Рассмотрим рабочий процесс ветрозащитного устройства, выполненного в виде плоской решетки, представляющей собой набор прямоугольных пластин, конгруэнтно смещенных вдоль прямой $M_{1} M_{2}$ (ось решетки) (рисунок 2).

Данное устройство позволяет изменить скорость и направление действующего на нее воздушного потока. При этом направление потока определяется углом установки пластин к оси решетки $\beta$ (рисунок 2а). Воздушный поток представим состоящим из отдельных одинаковых потоков, обтекающих пластины по линиям тока $A B C$ и $A_{1} B_{1} C_{1}$ (Гордеенко и Крук, 2006). 
Determination of optimal...

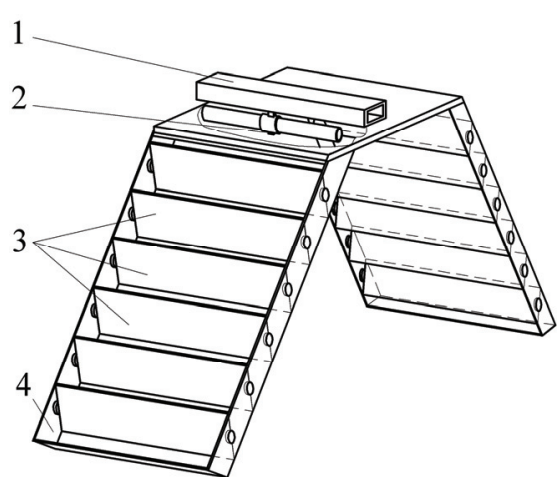

a)

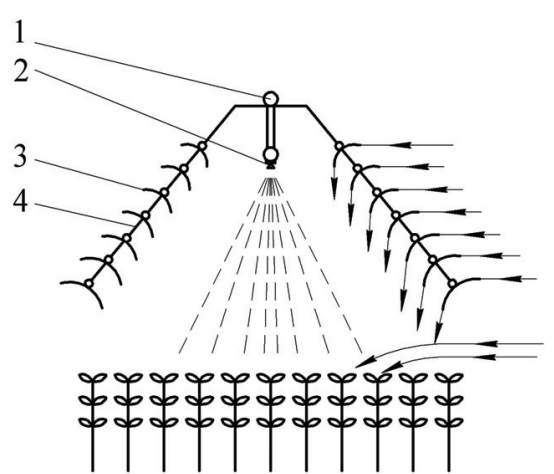

б)

Рисунок 1. Механические устройства защиты факела распыла от прямого воздействия ветра с помощью жалюзи в форме прямоугольных (а) и изогнутых (б) пластин: 1 - несущая конструкиия; 2 - распределительная штанга с распылителем; 3-пластины; 4-рамка

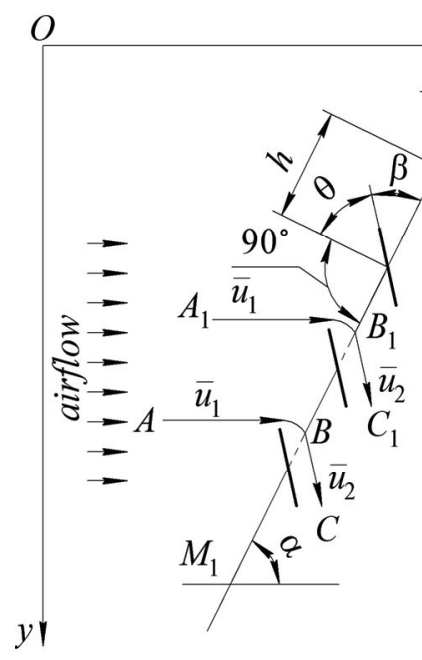

a) $\underline{x}$

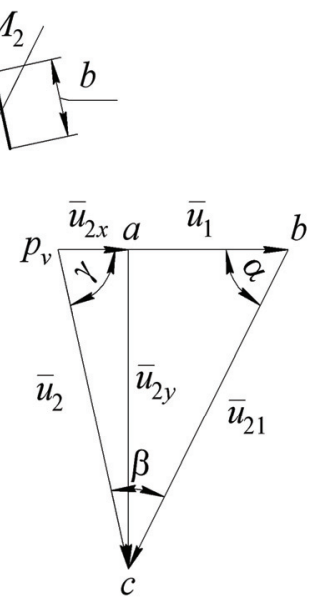

b)

Рисунок 2. Расчетная схема ветрозащитной решетки: а-схема установки решетки; $b$-общий вид плана скоростей воздушного потока 
Характер изменения скорости воздушного потока при поперечном обтекании пластин решетки определяется теоремой сложения скоростей:

$$
\bar{u}_{2}=\bar{u}_{1}+\bar{u}_{21}
$$

где:

$\bar{u}_{1}$ и $\bar{u}_{2}-$ соответственно векторы скоростей линий тока воздушного потока перед и за решеткой;

$\bar{u}_{21} \quad-$ вектор отклонения скоростей линий тока от первоначального направления, вызванного поперечным обтеканием пластин решетки.

Взаимосвязь между векторами уравнения (1) нетрудно установить по теореме синусов, представив его решение графически в виде плана скоростей с полюсом $p_{v}$ (рисунок 2б):

$$
\begin{gathered}
u_{2}=u_{1} \frac{\sin \alpha}{\sin \beta} \\
u_{21}=u_{1} \frac{\sin (\alpha+\beta)}{\sin \beta}
\end{gathered}
$$

где:

$\alpha \quad$ - угол наклона оси $M_{1} M_{2}$ решетки к горизонтальной оси,

$\beta-$ угол установки пластин относительно оси $M_{1} M_{2}$ решетки.

Для оценки воздействия воздушного потока, сформировавшегося за решеткой на факел распыленной жидкости, разложим вектор скорости $\bar{u}_{2}$, определяемый уравнением (1) по координатным осям $O x$ и $O y$ (рисунок 2б).

$$
\begin{aligned}
& u_{2 x}=u_{2} \cdot \cos \gamma=u_{1}\left[1-\frac{\sin (\alpha+\beta)}{\sin \beta} \cdot \cos \alpha\right] \\
& u_{2 y}=u_{2} \cdot \sin \gamma=u_{1} \cdot \frac{\sin (\alpha+\beta)}{\sin \beta} \cdot \sin \alpha
\end{aligned}
$$

где:

$\gamma \quad$ - угол между векторами скоростей $\bar{u}_{1}$ и $\bar{u}_{2}$.

По физической сущности проекция вектора скорости $\bar{u}_{2 y}$, определяемая уравнением (5), направлена вдоль оси $O y$ и способствует быстрейшему осаждению капель. Снос капель жидкости из факела распыла происходит под действием горизонтальной составляющей вектора скорости $\bar{u}_{2 x}$, определяемого уравнением (4). Из анализа уравнения (4) следует: 
Determination of optimal...

1) если $\gamma=180-(\alpha+\beta)<\frac{\pi}{2}$, то $u_{2 x}>0$, и капли жидкости будут сноситься из зоны обработки в сторону движения воздушного потока.

2) если $\alpha=\frac{\pi}{2}$ (ось решетки установлена перпендикулярно направлению движения воздушного потока), то $u_{2 x}=u_{1}$, и при любых значениях угла $\beta>0$ установки пластин эффективность ветрозащитной решетки равна нулю;

3) если $\gamma=180-(\alpha+\beta)>\frac{\pi}{2}$, то $u_{2 x}<0$, и капли жидкости будут перемещаться в сторону ветрозащитной решетки при любом значении скорости воздушного потока;

4) если $\beta=\frac{\pi}{2}$ (пластины установлены перпендикулярно оси решетки), то $u_{2 x}=u_{1} \cdot \sin ^{2} \alpha<u_{1}$, и интенсивность сноса капель из зоны обработки будет определяться только углом $\alpha$ наклона оси решетки.

5) если $\beta=0$, то при любых значениях угла $0<\alpha<\frac{\pi}{2}$ установки решетки, горизонтальная $u_{2 x}$ и вертикальная $u_{2 y}$ составляющие скорости воздушного потока достигают величины большей, чем скорость воздушного потока перед решеткой и факел распыленной жидкости будет смещен в сторону решетки.

Приведенный анализ показывает, что при определенном соотношении между углами $\alpha$ и $\beta$ за ветрозащитной решеткой можно создать условия движение капель рабочего раствора по требуемым траекториям в факеле распыла даже при скорости ветра перед решеткой, превышающей установленные ограничения. Во всех случаях следует обратить внимание на то, что при уменьшении угла $\alpha$ снос капель из зоны обработки снижается, а габариты ветрозащитной решетки возрастают. Уменьшение угла $\beta$ установки пластин приводит к резкому возрастанию вертикальной составляющей скорости воздушного потока за решеткой, что может привести к повреждению растений. Для проверки этих предположений была разработана конструкция, изготовлена лабораторная установка и проведены исследования по изменению направления движения горизонтального потока воздуха с помощью жалюзийной решетки. Лабораторная установка состоит из опрыскивателя, вентилятора, ветрозащитного устройства. В процессе проведения исследований использовались приборы для измерения скорости и давления потока воздуха, расхода жидкости (рисунок 3, 4).

Направленный воздушный поток создается центробежным вентилятором 1 (рисунок 3) с приводом от электродвигателя. Скорость воздушного потока регулируется дроссельным устройством, состоящим из заслонки и регулятора с ручным приводом. Данное устройство позволяет точно и плавно регулировать скорость выходящего воздушного потока от 0,5 до $10 \mathrm{M} \cdot \mathrm{c}^{-1}$. Скорость направленного потока воздуха перед решеткой 3 (рисунок 4) и ее горизонтальная составляющая за 
решеткой измерялись с помощью анемометра 6 (рисунок 3). Для количественной оценки параметров сноса жидкости лабораторная установка оборудована дополнительной приемной поверхностью 4, выполненной в форме желобов и установленной на одном уровне с приемной поверхностью макета гребня 3. Желобы в поперечном сечении представляют собой равносторонние треугольники со стороной 50 мм, изготовленные из оцинкованной стали.
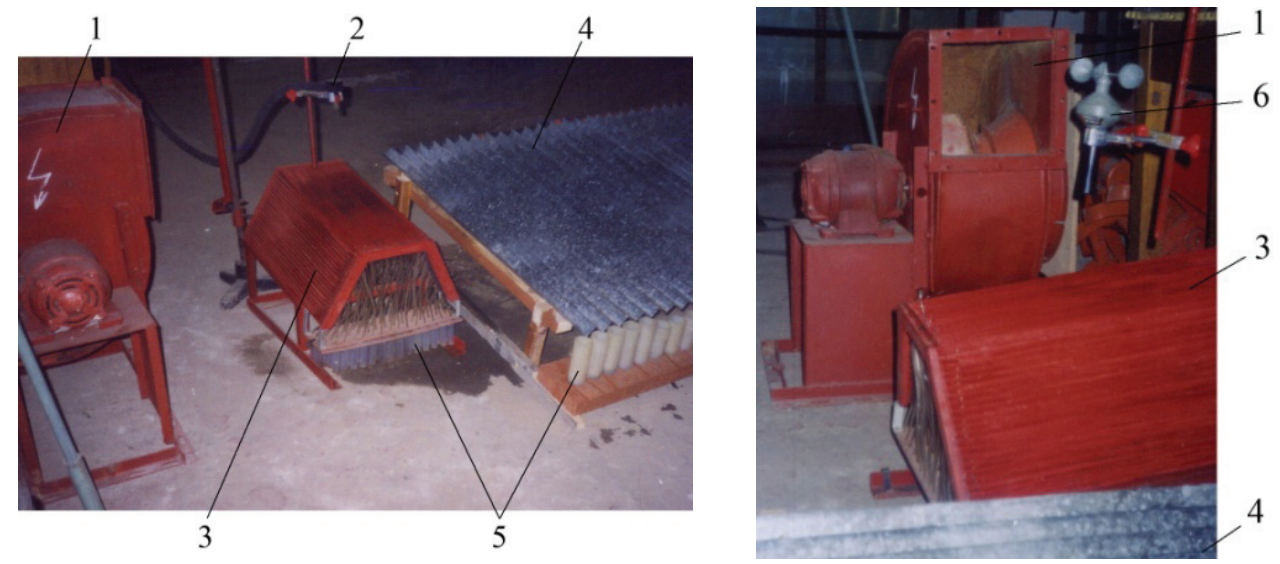

Рисунок 3. Лабораторная установка для определения сноса капель направленным воздушнылм потоком: 1 - вентилятор, 2 - узел крепления распьлителя, 3 - приемная поверхность в форме гребня, 4 - дополнительная приемная поверхность, 5 -мернье ичлиндрьи, 6-анемометр

Разность между объемами жидкости, прошедшей через распылитель и осевшей на приемную поверхность макета гребня, определяет ее снос из зоны обработки и характеризуется коэффициентом $k$ целевого использования распыленной жидкости.

Количественная оценка распределения жидкости за пределами зоны обработки при различной скорости воздушного потока без ветрозащитного устройства на примере трех распылителей представлена в таблице 1.

Анализ данных таблицы 1 показывает, что при воздействии направленного воздушного потока происходит перераспределение жидкости по объекту обработки. В опытах отмечено, что при номинальных условиях опрыскивания и скорости направленного воздушного потока 2 м $\mathrm{c}^{-1}$, свыше $10 \%$ и $19 \%$ жидкости, распыленной соответственно распылителями TP40015E и $30 H C X 3$, сносятся из зоны обработки на расстояние до 0,1 м и около $0,1 \%$ на расстояние более 1 метра. Свыше $5 \%$ жидкости, прошедшей через щелевой распылитель $T P 40015 E$, оседает на боковой поверхности макета гребня. Около 4\% распыленной жидкости оседает на расстоянии 0,2-0,5 м и около $2 \%$ распыленной жидкости сносится на расстояние более 0,5 м. Дальнейшее увеличение скорости воздушного потока приводит к резкому увеличению объема жидкости, выносимого за пределы зоны обработки. Например, при скорости воздушного потока $\mathrm{u}=7 \mathrm{M} \cdot \mathrm{c}^{-1}$ из зоны обработки сносится до $76 \%$ капель жидкости, генерируемых распылителем TP40015E. При этом снос за пределы контролируемой 
Determination of optimal...

зоны (дальше 1 метра от оси макета гребня) возрастает с 0,2\% (при $\mathrm{u}=2 \mathrm{~m} \cdot \mathrm{c}^{-1}$ ) до $13,1 \%$ (при $\left.\mathrm{u}=7 \mathrm{M} \cdot \mathrm{c}^{-1}\right)$.

Таблица 1.

Параметры сноса рабочей жидкости за предель требуемой зоны обработки

\begin{tabular}{|c|c|c|c|c|c|c|c|c|c|}
\hline \multirow{2}{*}{ 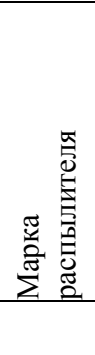 } & \multirow{2}{*}{ 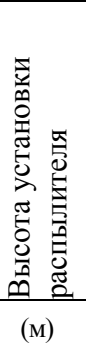 } & \multirow{2}{*}{ 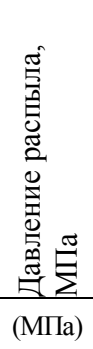 } & \multirow{2}{*}{ 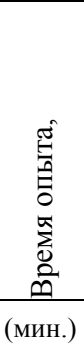 } & \multirow{2}{*}{ 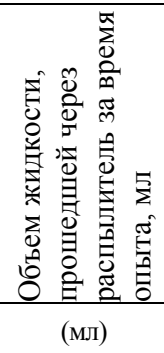 } & \multirow{2}{*}{ 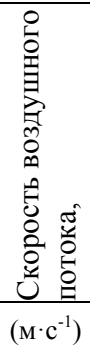 } & \multicolumn{4}{|c|}{$\begin{array}{l}\text { Количество жидкости (мл/\%), снесенной возд- } \\
\text { ушным потокам от оси симметрии гребня на } \\
\text { расстояние, ограниченное границами, (м) }\end{array}$} \\
\hline & & & & & & $0,1-0,2 \mathrm{M}$ & $0,2-0,5 \mathrm{M}$ & $0,5-1,0 \mathrm{M}$ & $>1,0 \mathrm{M}$ \\
\hline \multirow{6}{*}{ 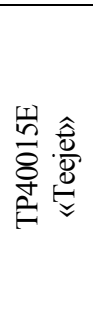 } & \multirow{6}{*}{0,4} & \multirow{6}{*}{0,3} & \multirow{6}{*}{30} & \multirow{6}{*}{6000} & 2 & $327 / 5,45$ & $239 / 3,98$ & $97 / 1,62$ & $6 / 0,1$ \\
\hline & & & & & 3 & $364 / 6,06$ & 486 / 8,1 & $640 / 10,7$ & $103 / 1,72$ \\
\hline & & & & & 4 & $504 / 8,4$ & $782 / 13,03$ & 844 / 14,07 & $412 / 1,86$ \\
\hline & & & & & 5 & $625 / 10,4$ & $804 / 13,4$ & 1014 / 16,9 & $1403 / 23,4$ \\
\hline & & & & & 6 & 742 / 12,37 & $883 / 14,72$ & $1258 / 20,97$ & $1719 / 28,65$ \\
\hline & & & & & 7 & 782 / 13,03 & $953 / 15,88$ & $1320 / 22,0$ & $2347 / 39,1$ \\
\hline \multirow{5}{*}{ 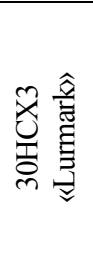 } & \multirow{5}{*}{0,3} & \multirow{5}{*}{0,3} & \multirow{5}{*}{30} & \multirow{5}{*}{5970} & 2 & $601 / 10,4$ & $390 / 6,73$ & $120 / 2,07$ & $6 / 0,1$ \\
\hline & & & & & 3 & $811 / 14,0$ & $826 / 14,26$ & $285 / 4,92$ & $143 / 2,47$ \\
\hline & & & & & 4 & $976 / 16,85$ & $904 / 15,61$ & $576 / 9,95$ & $428 / 7,4$ \\
\hline & & & & & 5 & $1439 / 24,85$ & $1074 / 18,55$ & 742 / 12,81 & $692 / 11,95$ \\
\hline & & & & & 6 & $1586 / 27,39$ & $1210 / 20,9$ & $1160 / 20,03$ & $833 / 14,38$ \\
\hline \multirow{5}{*}{ 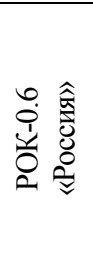 } & \multirow{5}{*}{0,15} & \multirow{5}{*}{0,3} & \multirow{5}{*}{10} & \multirow{5}{*}{4800} & 3 & $140 / 2,92$ & $70 / 1,46$ & $41 / 0,85$ & $7 / 0,15$ \\
\hline & & & & & 4 & $576 / 12$ & $369 / 7,7$ & $266 / 5,5$ & $56 / 1,17$ \\
\hline & & & & & 5 & $872 / 18,2$ & $720 / 15,0$ & $568 / 11,8$ & $322 / 6,7$ \\
\hline & & & & & 6 & $1138 / 23,7$ & $980 / 20,4$ & $560 / 11,7$ & $416 / 8,7$ \\
\hline & & & & & 7 & $1360 / 28,3$ & $958 / 20,0$ & $760 / 15,8$ & $580 / 12,1$ \\
\hline
\end{tabular}

Объем жидкости, прошедший через распылитель $30 H C X 3$ и снесенный воздушным потоком $\left(\mathrm{u}=2 \mathrm{~m} \cdot \mathrm{c}^{-1}\right)$ на расстояние $0,1-0,2$ и 0,2-0,5 метра от центра макета гребня, соответственно составляет 5,45 и 4,95\%. Снос жидкости на расстояние более 0,5 метра, составляет около $0,1 \%$. С увеличением скорости воздушного потока до $6 \mathrm{~m} \cdot \mathrm{c}^{-1}$ снос капель жидкости возрастает до 80-83\%. При этом около $18 \%$ жидкости сносится на расстояние более 1 метра. Это примерно в 2 раза меньше объема жидкости, снесенного воздушным потокам с аналогичными параметрами, воздействующим на факел распылителя TP40015E. 
Данное явление объясняется двумя причинами:

- различием высоты установки распылителей над поверхностью макета гребня;

различием в форме факела распыла: плоский факел распылителя TP40015E менее устойчив к воздействию воздушного потока, чем конусообразный факел распылителя 30НСХ3, что многократно отмечено при проведении опытов.

Экспериментально установлено, что воздействие воздушного потока $\left(u \leq 2 \mathrm{M} \cdot \mathrm{c}^{-1}\right)$ на факел распылителя $P O K-0.6$, практически не приводит к перераспределению жидкости, оседающей на поверхность макета гребня. Заметные изменения в распределении жидкости по поверхности макета гребня наступают при скорости воздушного потока более $4 \mathrm{~m} \cdot \mathrm{c}^{-1}$. Из данных, приведенных в таблице 1 видно, что при скорости воздушного потока $u=4 \mathrm{M} \cdot \mathrm{c}^{-1}$ с обрабатываемой поверхности сносится около 5\% жидкости, прошедшей через распылитель $P O K-0.6$, что примерно в 5-7 раз меньше, чем при использовании распылителей $T P 40015 E$ и $30 H C X 3$ в аналогичных условиях работы. Увеличение скорости воздушного потока с 4 до $7 \mathrm{~m} \cdot \mathrm{c}^{-1}$ приводит к увеличению сноса жидкости из зоны обработки до 24-75\%. Из приведенного анализа следует, что факел жидкости распылителя $P O K-0.6$ более устойчив к воздействию воздушного потока, чем факелы распылителей TP40015E и $30 H C X 3$.

Ветрозащитное устройство, выполненное в виде жалюзийной решетки 3 (рисунок 4) представляет собой жесткую прямоугольную раму размером $1200 \times 1200$ мм. С шагом 100 мм в раме установлено 12 связанных между собой пластин размером $1195 \times 120$ мм. Путем поворота вокруг своих осей пластины относительно рамы могут устанавливаться и фиксироваться под углом 0-180 . Решетка с помощью кронштейнов и стоек может быть установлена к горизонту под углом 0-90. Высота установки решетки и расстояние до поверхности макета гребня регулируется путем перемещения кронштейнов вдоль стоек.

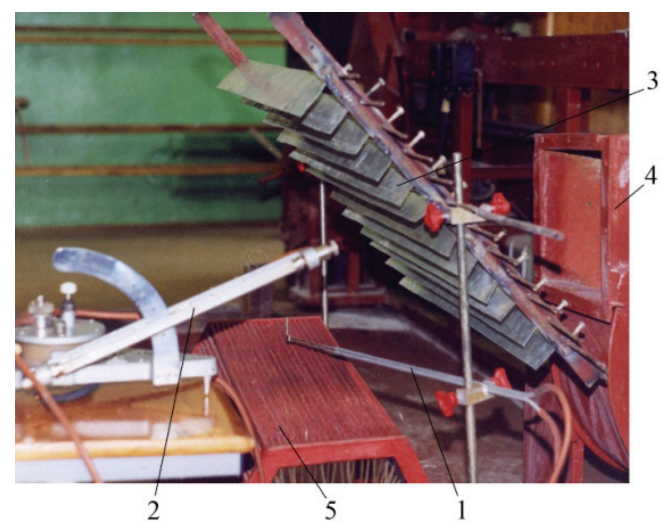

Рисунок 4. Измерение динамического давления воздушного потока: 1 трубка Пито, 2 - микроманометр, 3 ветрозащитная решетка, 4 - вентилятор, 5 -макет гребня

Вертикальная составляющая скорости потока за ветрозащитной решеткой определялась динамическим давлением воздуха на поверхность макета гребня.

При нормальных атмосферных условиях связь между динамическим давлением и скоростью потока воздуха определяются соотношением (Гордеенко, 2004): 
Determination of optimal...

$$
u=1,29 \sqrt{P_{\text {din }}}
$$

где:

$P_{d i n}-$ динамическое давление в контролируемой точке воздушного потока, (Па)

Для измерения динамического давления воздушного потока за ветрозащитной решеткой использовался жидкостный лабораторный микроманометр и трубка Пито (рисунок 4). Динамическое давление и скорость воздуха за ветрозащитной решеткой определялись при скоростном напоре потока, создаваемого вентилятором перед решеткой $\left(u=4-10 \mathrm{M} \cdot \mathrm{c}^{-1}\right)$, при последовательном изменении установочных углов в пределах в соответствии с анализом уравнения (4).

Сопоставляя данные, полученные в опытах с различными распылителями, отметим, что воздействуя ветрозащитной решеткой на воздушный поток можно повысить коэффициент целевого использования жидкости даже при скорости ветра 6 $\mathrm{M} \cdot \mathrm{c}^{-1}$. Так при установке оси решетки под углом $45^{\circ}$ к горизонту и скорости воздушного потока $4 \mathrm{~m} \cdot \mathrm{c}^{-1}$, коэффициент целевого использования жидкости повышается с $52 \%$ (без решетки) до 70,4\% (таблица 2). В сравнении с неподвижной средой этот показатель меньше на $1,2 \%$. При увеличении скорости воздушного потока с 4 до $6 \mathrm{~m} \cdot \mathrm{c}^{-1}$ и неизменных параметрах распыла и установки решетки, коэффициент целевого использования жидкости повышается с 29,7\% (без ветрозащитного устройства) до $61 \%$, что на $10,6 \%$ меньше, чем в неподвижной среде. Увеличение угла наклона оси решетки с $45^{\circ}$ до $60^{\circ}$ приводит к незначительному уменьшению коэффициента целевого использования на $6,4 \%$ и $10 \%$ соответственно при скорости воздушного потока в 4 и $6 \mathrm{~m} \cdot \mathrm{c}^{-1}$.

Следует также отметить, что при изменении угла установки решетки в пределах 45-60 ${ }^{\circ}$ и скорости воздушного потока 4-6 м $\mathrm{c}^{-1}$, асимметрия отложения жидкости по поверхности гребня, характерная при распыле жидкости без защиты факела, заметно снижается.

Таким образом, экспериментально установлено, что с помощью ветрозащитной решетки можно увеличить коэффициент целевого использования и равномерность распределения рабочего раствора по обрабатываемой поверхности при проведении обработок в ветреную погоду.

Таблица 2.

Влияние ветрозащчитной решетки на коэффищчиент целевого использования (на примере распьлителя ТР40015E)

\begin{tabular}{|c|c|c|c|c|c|c|c|c|c|}
\hline 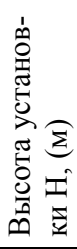 & 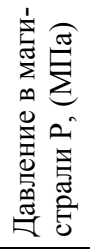 & 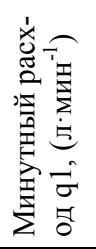 & 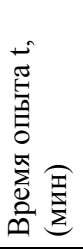 & 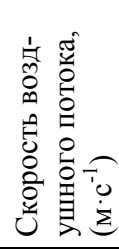 & 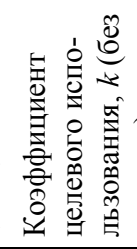 & 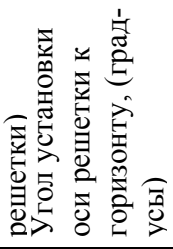 & 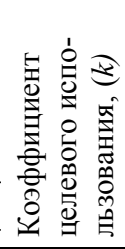 & 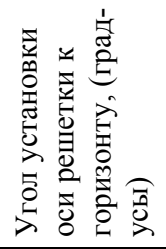 & 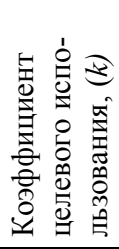 \\
\hline \multirow{3}{*}{0,4} & \multirow{3}{*}{0,3} & \multirow{3}{*}{0,6} & \multirow{3}{*}{30} & 0 & 0,716 & \multirow{3}{*}{$45^{\circ}$} & 0,716 & \multirow{3}{*}{$60^{\circ}$} & 0,716 \\
\hline & & & & 4 & 0,520 & & 0,704 & & 0,648 \\
\hline & & & & 6 & 0,297 & & 0,610 & & 0,513 \\
\hline
\end{tabular}




\section{Заключение}

В статье приведены результаты исследований по обоснованию конструктивных параметров ветрозащитного устройства, выполненного в виде жалюзийной решетки с прямоугольными пластинами. Установлено, что использование данного устройства возможно при скорости ветра, превышающей допустимую агротехникой возделывания.

\section{Литература}

Гордеенко, О.В., Крук, И.С., Титов, Ю.И., Каминский, Э., Новиков, А.А. (2011). Методика инженерного расчета кинематических параметров движения капель рабочего раствора пестицидов в воздушной среде. Агропанорама, 6, 6-10.

Гордеенко, О.В., Крук, И.С., Кот, Т.П., Каминский, Э., Романюк, В. (2014). Методика инженерного расчета кинематических параметров движения капель рабочего раствора пестицидов в подвижной воздушной среде. Агропанорама, 5, 24-28.

Гордеенко, О.В., Кот, Т.П., Крук, И.С., Маркевич, А.Е. (2007). Способы и устройства защиты факела распыла при внесении пестицидов в ветреную погоду. Механизация и электрификация сельского хозяйства. Межведомственный тематический сборник. Bыnycк, 41, 106-113.

Крук, И.С., Послед, Е.В., Кот, Т.П., Гордеенко, О.В., Маркевич, А.Е. (2009). Снижение потерь пестицидов из-за сноса при проведении обработок в неблагоприятных погодных условиях. Материалы межд. научн.-практ. конф. «Экология и сельскохозяйственная техника». СанктПетербург: СЗНИИМЭСХ, т. 2, 50-57.

Гордеенко, О.В., Послед, Е.В., Новиков, А.А. (2010). Обоснование способов защиты факела распыла от воздействия ветра. Материалы межд. научн.-практ. конф. «Современная сельскохозяйственная техника: исследование, проектирование, применение». Мн.: БГАТУ, т. 1, 119-122.

Kaminski, E., Kruk, I. (2011). Sposoby zapobiegania znoszeniu cieczy roboczej podczas zabiegów ochrony roslin. Technika rolnicza ogrodnicza i leśna, 4, 25-26.

Крук, О.В., Гордеено, Е.В., Послед и др. (2010). Штанга опрыскивателя с ветрозащитными устройствами. ВY № 6648, МПК А 01М 7/00 / И.С. Заявитель Белорусск. гос. аграрн. техн. ун-т. № u20100267, заявл. 18.03.2010, опубл. 30.10.2010. Нач. иэнтр інтэлектуал. Уласиівасиі. 5(76), 161.

И.С. Крук, В.А. Агейчик, Д.Р. Мальцев, О.В. (2013). Штанга опрыскивателя с ветрозащитным устройством. пат. ВY № 9714, МПК А 01М 7/00 / Гордеенко; заявитель Белорусск. гос. аграрн. техн. ун-т. № u20130442, заявл. 28.05.2013, опубл. 30.12.2013. Нац. иэнтр інтэлектуал. Уласиівасиі, 6(95), 171.

Гордеенко, О.В., Крук, И.С. (2006). Защита факела распыленного пестицида от сноса воздушным потоком. Инженерный вестник, 2(22), 14-18.

Гордеенко, О.В. (2004). Повышение эффективности ухода за посевами овощных культур на гребнях совериенствованием оборудования для ленточного внесения гербицидов: Дис. ...канд. Техн. Наук. БГСХА. Горки, 218 с. 
Determination of optimal...

\section{OKREŚLENIE OPTYMALNYCH GEOMETRYCZNYCH PARAMETRÓW WIATROCHRONNEGO URZĄDZENIA OGRANICZAJĄCEGO ZNOSZENIE PREPARATU PRZEZ WIATR PRZY OPRYSKU HERBICYDAMI}

Streszczenie. Celem pracy było określenie optymalnych geometrycznych parametrów wiatrochronnego urządzenia ograniczającego znoszenie preparatu przez wiatr przy oprysku herbicydami. Badania przeprowadzono z wykorzystaniem metod planowania eksperymentów i statystycznych metod przetwarzania uzyskanych wyników. Rezultatem badan było uzyskanie parametrów konstrukcyjnych wiatrochronu wykonanego w kształcie kraty żaluzjowej z prostokątnymi płytami. Stwierdzono, że urządzenie to, może być stosowane przy prędkości wiatru przewyższającej dopuszczalne wielkości agrotechniczne. Wyniki badań znajdą zastosowanie w pracach nad urządzeniami do ochrony przed wiatrem przy precyzyjnym podawaniu herbicydów.

Słowa kluczowe: kropla, przepływ, prędkość, ruch, trajektoria, znoszenie, urządzenie wiatrochronne 